\title{
Assessment by Using a Water-Soluble Contrast Enema Study of Radiologic Leakage in Lower Rectal Cancer Patients With Sphincter-Saving Surgery
}

\author{
Seok In Seo, Jong Lyul Lee ${ }^{1}$, Seong Ho Park ${ }^{2}$, Hyun Kwon $\mathrm{Ha}^{2}$, Jin Cheon Kim ${ }^{1}$ \\ Department of Surgery, Veterans Health Service Medical Center, Seoul; Departments of ${ }^{1}$ Surgery and ${ }^{2}$ Radiology, Asan Medical Center, \\ University of Ulsan College of Medicine, Seoul, Korea
}

Purpose: This study evaluated the efficacy of a water-soluble contrast enema (WCE) in predicting anastomotic healing after a low anterior resection (LAR).

Methods: Between January 2000 and March 2012, 682 consecutive patients underwent a LAR or an ultra-low anterior resection (ULAR) and were followed up for leakage. Clinical leakage was established by using physical and laboratory findings. Radiologic leakage was identified by using retrograde WCE imaging. Abnormal radiologic features on WCE were categorized into four types based on morphology: namely, dendritic, horny, saccular, and serpentine.

Results: Of the 126 patients who received a concurrent diverting stoma, only two (1.6\%) suffered clinical leakage due to pelvic abscess. However, 37 patients $(6.7 \%)$ in the other group suffered clinical leakage following fecal diversion $(\mathrm{P}=$ 0.027). Among the 163 patients who received a fecal diversion, 20 showed radiologic leakage on the first WCE (eight with and 12 without a concurrent diversion); 16 had abnormal features continuously until the final WCE while four patients healed spontaneously. Eleven of the 16 patients (69\%), by their surgeon's decision, underwent a stoma restoration based on clinical findings ( $2 / 3$ dendritic, 3/4 horny, 5/7 saccular, $1 / 2$ serpentine). After stoma reversal, only 2 of the 11 (19\%) complained of complications related to the rectal anastomosis.

Conclusion: WCE is helpful for detecting radiologic leakage before stoma restoration, especially in patients suffering clinical leakage after an uLAR. However, surgeons appear to opt for stoma restoration despite the persistent existence of radiologic leakage in cases with particular features on the WCE.

Keywords: Rectal neoplasms; Colorectal surgery; Anastomotic leak; Contrast radiography

\section{INTRODUCTION}

Anastomotic leakage is a catastrophic complication after sphincter-saving rectal surgery and occurs in $1 \%-24 \%$ of cases [1-4]. For an ordinary low anterior resection (LAR), a diverting stoma is not

Received: May 7, 2015 - Accepted: August 4, 2015

Correspondence to: Jin Cheon Kim, M.D.

Department of Surgery, Asan Medical Center, University of Ulsan College of Medicine and Institute of Innovative Cancer Research, 88 Olympic-ro 43-gil, Songpa-gu, Seoul 05505, Korea

Tel: +82-2-3010-3489, Fax: +82-2-474-9027

E-mail: jckim@amc.seoul.kr,

(C) 2015 The Korean Society of Coloproctology

This is an open-access article distributed under the terms of the Creative Commons Attribution NonCommercial License (http://creativecommons.org/licenses/by-nc/3.0) which permits unrestricted noncommercial use, distribution, and reproduction in any medium, provided the original work is properly cited. routinely necessary. However, for an ultra-low anterior resection ( $\mathrm{uLAR}$ ), the use of a diverting stoma is increasing. Surgeons generally employ a diverting stoma to protect the anastomosis due to the possibility of anastomosis-related septic complications. Many studies have shown that diverting stomas are safe and that they are effective in preventing anastomotic leakage after sphinctersaving surgery [2, 3, 5-9]. However, some studies have shown that they may not prevent postoperative anastomotic leakage, but rather reduce the incidence of severe sequelae caused by leakage [10-12].

Prior to the restoration of a diverting stoma, a water-soluble contrast enema (WCE) is routinely performed as an effective radiologic procedure for identifying a leaking anastomosis [13]. In cases of a leakage on the WCE, surgeons generally do not try stoma restoration, but wait until the leak site is completely obliter- 
ated. On the other hand, several investigators have reported that a routine WCE is unnecessary [14-17]. We have noted some abnormal findings on WCEs without any clinical symptoms of leakage after restoration of the stoma. Interpretation of these radiologic features may be difficult, and these features may vaguely be considered as contraindications for restoration, but the specific features of any abnormal findings seen on a retrograde WCE that contraindicate restoration of a stoma have not been accurately defined. This study was designed to evaluate the efficacy of a WCE in accurately predicting anastomotic healing in patients who have undergone an uLAR for rectal cancer and to identify specific abnormal findings on a retrograde WCE that might permit stoma restoration.

\section{METHODS}

\section{Eligibility and enrollment}

Between January 2000 and March 2012, 682 patients underwent a curative LAR or uLAR for low rectal cancer performed by a single rectal surgeon who had performed at least 120 rectal cancer operations per year for more than 20 years at a single center. All of the pelvic dissections were performed below the puborectal ring. For an ULAR, the anastomotic line is located below the pelvic floor muscle, including intersphincteric resection. The median followup period was 34 months (range, 1-131 months). A total of 126 patients received a concurrent diverting ileostomy. The other 556 patients did not receive a concurrent fecal diversion.

\section{Surgery}

Preoperative chemoradiotherapy (CRT) with postoperative adjuvant chemotherapy was indicated in patients with stage III or greater lower rectal cancer preoperatively. Any patient with $\geq$ stage III cancer who had not received CRT preoperatively was administered postoperative adjuvant CRT. Patients receiving preoperative CRT were given a total of 40-50.4 Gy with 5-fluorouracil + leucovorin or capecitabine, and surgery was performed 5 to 8 weeks after completion of this treatment. Symptomatic obstruction occurred in two patients during the work-up period, and they underwent a diverting stoma surgery before receiving preoperative CRT.

Of the 682 patients, 99 underwent a robot-assisted ULAR while 583 underwent an open LAR or uLAR. A laparoscopy-assisted operation was not performed for an ULAR. All anastomoses were formed by using the double stapling technique, except for 10 cases with a coloanal anastomosis. After the anastomosis, the completeness of the doughnut was inspected by the surgeon, and anastomotic leakage was confirmed by the presence of bubbles in the saline-filled pelvic cavity when air insufflations were made through the anus. Air leaks were repaired with reinforcement sutures at the leak point until air leakage ceased. The surgeon opted for a diverting ileostomy intraoperatively when patients had more than one of the following conditions: excessive tension, poor blood supply, a positive air leak, preoperative CRT, or a severe comorbidity.

\section{Follow-up and definition of leakage}

Clinical leakage was defined as peritonitis caused by leakage, pelvic abscess, or discharge of fecal material from intra-abdominal drainage postsurgery. Symptoms and signs included abdominal pain, distension, tachycardia, fever, leucocytosis, and elevated Creactive protein. When these symptoms and signs were present, abdomino-pelvic computed tomography (CT) was performed to identify abnormal collections of fluid or air bubbles at the anastomotic site. In the case of clinical leakages without a concurrent diverting ileostomy, patients underwent a diverting ileostomy, intraoperative irrigation, and drainage catheter insertion and were treated with antibiotic therapy. On the other hand, patients who suffered from clinical leakage despite a concurrent diverting ileostomy were treated with long-term antibiotic therapy without additional surgery.

Retrograde WCE and digital rectal examination were performed three to four months after the ULAR or approximately one month after the completion of adjuvant chemotherapy. When these examinations revealed an intact anastomosis without stricture or recurrence, restoration of the diverting stoma was accomplished. Conversely, if a leak or stenosis was observed, closure was postponed until the leak site had been completely obliterated on serial WCEs that were repeated every 3 months or until stenosis had been improved by manual or Hegar dilatation. Radiologic leakage was defined as the presence of contrast leakage or a fistula on a retrograde WCE. All WCEs were reviewed by specialized radiologists before stoma restoration.

After stoma restoration, patients were followed up at six-month intervals. If a diverting ileostomy was present after 12 months without any documented decision regarding its restoration, it was considered as a permanent stoma. Otherwise, reinstallation of a stoma due to severe complications after stoma restoration was considered to make it permanent. Abnormal radiologic images on a retrograde WCE were retrospectively categorized into four types according to morphologic features: dendritic, horny, saccular, and serpentine (Fig. 1). The dendritic type was defined by its having multiple and multidirectional linear tracks while the horny type was defined by its forming a cavity with a blind end at a sharp angle. The saccular type had a blind, round and smooth cavity while the serpentine type formed a single track with a straight or winding feature.

\section{Statistics}

Categorical variables were analyzed with the chi-square test and Fisher exact test. Continuous variables were analyzed with the Student t-test and the Mann-Whitney U-test. P-values $<0.05$ were considered statistically significant. All statistical calculations were performed with IBM SPSS Statistics ver. 19.0 (IBM Co., Armonk, NY, USA). 

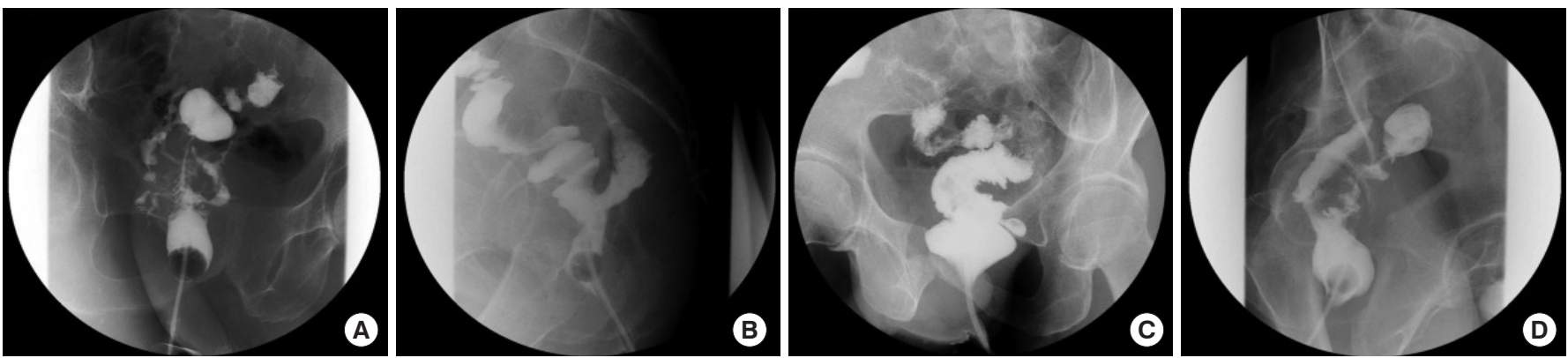

Fig. 1. Four types of radiologic leakages on a retrograde water-soluble contrast enema: (A) dendritic type, (B) horny type, (C) saccular type, and (D) serpentine type.

Table 1. Clinicopathologic characteristics of patients with clinical or radiological leakage

\begin{tabular}{lccc}
\hline Variable & $\begin{array}{c}\text { Clinical leakage } \\
(\mathrm{n}=39)\end{array}$ & $\begin{array}{c}\text { Radiological } \\
\text { leakage } \\
(\mathrm{n}=20)\end{array}$ & P-value \\
\hline Age (yr), mean & 57 & 58 & 0.595 \\
Male sex & $30(76.9)$ & $18(90.0)$ & 0.222 \\
\hline $\begin{array}{l}\text { Preoperative CRT patients } \\
\text { Postoperative CRT patients }\end{array}$ & $13(33.3)$ & $11(55)$ & 0.093 \\
$\begin{array}{l}\text { Tumor location from AV (cm), } \\
\quad \text { median (range) }\end{array}$ & $9.8(23.1)$ & $3(15)$ & 0.734 \\
$\begin{array}{l}\text { Anastomosis level from AV (cm), } \\
\quad \text { median (range) }\end{array}$ & $2.9(1.5-4.5)$ & $2.7(1.5-5)$ & 0.244 \\
$\begin{array}{l}\text { Concurrent fecal diversion } \\
\text { Stoma restoration }\end{array}$ & $2(5.1)$ & $8(40.0)$ & $0.002^{*}$ \\
$\begin{array}{l}\text { Stoma restoration postsurgery (mo), } \\
\quad \text { mean }\end{array}$ & $73(84.6)$ & $13(65.0)$ & 0.106 \\
\hline $\begin{array}{l}\text { Pathologic T3-4 } \\
\text { Pathologic N1-2 }\end{array}$ & $23(67.6)$ & $9(56.3)$ & 0.532 \\
\hline Operation type, open & $10(29.4)$ & $3(15.8)$ & 0.334 \\
\hline
\end{tabular}

Values are presented as number (\%) unless otherwise indicated.

$\mathrm{CRT}$, chemoradiation therapy; $\mathrm{AV}$, anal verge.

aCancer staging according to the American Joint Committee on Cancer (7th ed., 2010).

${ }^{*} \mathrm{P}<0.05$

\section{RESULTS}

Patient outcomes in terms of clinical and radiologic leakage A flux diagram was used to present outcomes for all patients and for patients with radiologic leakage (Table 1) (Fig. 2A, B). The rate of concurrent fecal diversion was $18.5 \%$ (126 of 682 patients). A total of 39 patients from among the 682 enrolled patients $(5.7 \%)$ suffered from clinical leakage, including 16 patients with overt peritonitis and 23 with a pelvic abscess or fistula. Of the concurrent fecal diversion group, only two patients ( 2 of 126, 1.6\%) suffered from clinical leakage due to a pelvic abscess. However, 37 of the remaining 556 patients without a concurrent diversion $(6.7 \%)$ suffered from clinical leakage $(\mathrm{P}=0.027)$. All of the 37 patients who suffered from clinical leakage underwent additional surgery concurrently with antibiotic therapy. However, of the two patients suffering from clinical leakage despite a concurrent diversion, one patient underwent percutaneous abscess drainage; the other patient was treated with antibiotic therapy alone and did not undergo stoma restoration.

Of the 20 patients who had radiologic leakage on a retrograde WCE, 8 (40\%) received a concurrent fecal diversion, and 14 (70\%) suffered symptomatic clinical leakage. The radiologic leakage rate was greater in those patients who underwent a fecal diversion following clinical leakage than in the concurrent fecal diversion group ( 12 of 37 [32.4\%] vs. 6 of 126 [4.7\%], P < 0.001). In 4 of the 20 patients who had radiologic leaks on their retrograde WCE, the leakage healed spontaneously. Eleven of the 16 patients who had a persistent radiologic leakage underwent stoma reversal due to favorable clinical findings, and 9 of these 11 suffered no complication. In the end, 13 patients (65\%) avoided carrying permanent stomas: seven patients belonged to the group with radiologic leakage following clinical leakage and without concurrent fecal diversion, one patient had clinical leakage despite concurrent fecal diversion, and five belonged to the group with radiologic leakage only.

\section{Clinical features associated with leakage}

Closure of ileostomies was performed a median of 6 months (range, 1-43 months) after fecal diversion. Fecal diversion following clinical leakage was performed at a median of 7 days (range, 1-1,043 days) after an ULAR while the retrograde WCE was carried out at a median of 5 months (range, 1-41 months) after fecal diversion. Comparison between the clinical and the radiological leakage groups showed that they only differed significantly in terms of the concurrent fecal diversion rate $(\mathrm{P}=0.002)$ (Table 1$)$.

\section{Radiologic leakage}

Typical images of the respective types of radiologic leakage on the retrograde WCE are shown in Fig. 1 . Of the 20 patients with radiologic leakage, 3 presented with the dendritic type, 5 with the 


\section{$\begin{array}{rlr}\text { Annals of } & \text { Cancer Patients } W \\ \text { Coloproctology } & \text { Seok In Seo, et al. }\end{array}$
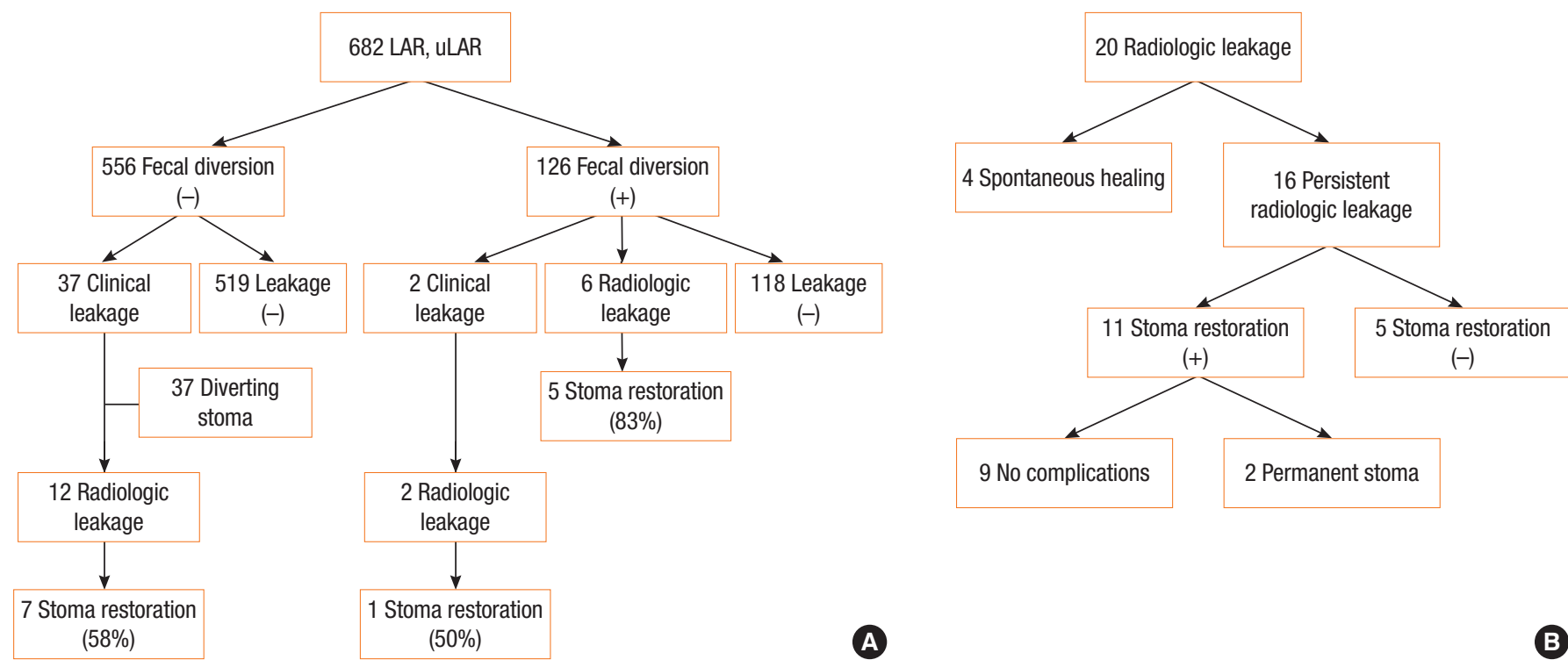

Fig. 2. Patient's algorithm according to anastomotic leakage: (A) clinical or radiologic leakage after surgery and (B) 20 patients with radiologic leakage. LAR, low anterior resection; ULAR, ultra-low anterior resection.

Table 2. Characteristics and outcomes for 20 patients with radiologic leakage

\begin{tabular}{|c|c|c|c|c|c|c|c|c|c|c|c|}
\hline Case & $\begin{array}{l}\text { Leakage } \\
\text { type }\end{array}$ & Sex & $\begin{array}{r}\text { Age } \\
(y r)\end{array}$ & $\begin{array}{l}\text { Concurrent } \\
\text { fecal } \\
\text { diversion }\end{array}$ & $\begin{array}{l}\text { Radiologic } \\
\text { leakage only }\end{array}$ & $\begin{array}{c}\text { Fecal } \\
\text { diversion } \\
\text { after 1st } \\
\text { operation (day) }\end{array}$ & $\begin{array}{l}\text { Spontaneous } \\
\text { healing of } \\
\text { anastomotic } \\
\text { site }\end{array}$ & $\begin{array}{c}\text { Stoma } \\
\text { restoration }\end{array}$ & $\begin{array}{c}\text { Stoma } \\
\text { restoration } \\
\text { after diversion } \\
(\mathrm{mo})\end{array}$ & $\begin{array}{c}\text { Complication } \\
\text { after } \\
\text { restoration }\end{array}$ & $\begin{array}{l}\text { Permanent } \\
\text { stoma }^{\mathrm{a}}\end{array}$ \\
\hline 1 & Dendritic & $\mathrm{M}$ & 58 & - & - & 466 & - & - & - & & + \\
\hline 2 & Dendritic & M & 57 & + & - & 0 & - & + & 10 & Stricture & + \\
\hline 3 & Dendritic & M & 70 & - & - & 4 & - & + & 6 & - & - \\
\hline 4 & Horny & M & 67 & - & - & 135 & - & - & - & & + \\
\hline 5 & Horny & M & 54 & + & + & 0 & + & + & 5 & - & - \\
\hline 6 & Horny & M & 50 & - & - & 39 & - & + & 13 & - & - \\
\hline 7 & Horny & $\mathrm{M}$ & 72 & - & - & 53 & - & + & 3 & - & - \\
\hline 8 & Horny & $\mathrm{F}$ & 51 & + & + & 0 & - & + & 10 & - & - \\
\hline 9 & Saccular & $M$ & 63 & - & - & 8 & - & + & 3 & - & - \\
\hline 10 & Saccular & M & 65 & + & + & 0 & - & - & - & & + \\
\hline 11 & Saccular & $M$ & 63 & + & + & 0 & + & + & 4 & - & - \\
\hline 12 & Saccular & M & 48 & - & - & 23 & - & + & 3 & - & - \\
\hline 13 & Saccular & M & 66 & - & - & 239 & - & - & - & & + \\
\hline 14 & Saccular & M & 54 & - & - & 3 & - & + & 8 & Abscess & + \\
\hline 15 & Saccular & $M$ & 64 & + & + & 0 & - & + & 9 & - & - \\
\hline 16 & Saccular & M & 59 & + & - & 0 & - & + & 9 & - & - \\
\hline 17 & Serpentine & M & 67 & - & - & 89 & - & - & - & & + \\
\hline 18 & Serpentine & M & 44 & - & - & 2 & + & + & 8 & - & - \\
\hline 19 & Serpentine & M & 39 & - & - & 17 & - & + & 3 & - & - \\
\hline 20 & RVF & $\mathrm{F}$ & 54 & + & + & 0 & + & + & 10 & - & - \\
\hline
\end{tabular}

RVF, recto-vaginal fistula.

aPeriod of stoma retention $>12$ months or stoma reinstallation due to severe complications. 
horny type, 8 with the saccular type, and 3 with the serpentine type; 1 presented with a recto-vaginal fistula (Table 2). Only two patients (10\%) were female. The recto-vaginal fistula healed spontaneously. However, spontaneous healing was rare in the other types, with the anastomotic leakage healing spontaneously in only three patients. Interestingly, we did not found the dendritic or the serpentine type among the six patients who carried radiologic leakages without clinical leakage.

Of the 16 patients who had abnormal features on the final retrograde WCE, 11 (69\%) underwent stoma restoration as a result of the surgeon's decision, which was based on the clinical and the radiologic findings ( 2 of 3 dendritic, 3 of 4 horny, 5 of 7 saccular, 1 of 2 serpentine). After stoma reversal, 9 of these 11 patients (81\%) experienced no signs or symptoms of anastomosis-related complications ( 1 of 2 dendritic, 3 of 3 horny, 4 of 5 saccular, 1 of 1 serpentine).

\section{DISCUSSION}

Anastomotic leakage is a major adverse event after a sphinctersaving operation for rectal cancer [6]. Furthermore, anastomosis leakage is an independent prognostic factor for local recurrence [18-20]. One study reported that patients with anastomosis leakage had a significantly reduced long-term survival, possibly because adjuvant chemotherapy had been delayed or abandoned [1] . These anastomotic leakages correspond to clinical leakages. Many studies have shown that a diverting stoma decreases the rate of clinical leakage and have recommended it use in sphincter-saving operations for rectal cancer [2, 3, 5-9]. Furthermore, 3 to $60 \%$ percent of patients who suffer from clinical leakage should never undergo a stoma restoration [21-23].

In our group of patients who received a fecal diversion, only 2 (1.6\%) suffered from clinical leakage in the form of a pelvic abscess whereas 37 of the remaining 556 patients without a concurrent diversion (6.7\%) suffered from clinical leakage $(\mathrm{P}=0.027)$. Thus, surgeons need to consider seriously the construction of a diverting stoma after an ULAR, specifically in cases with anastomotic fragility. On the other hand, among the cases including radiologic leakage, the leakage rates in the two groups were similar (6.3\% and 6.7\%, respectively, P > 0.999). According to the Expanded Accordion Severity Grading System, all clinical leakages after an ULAR without fecal diversion complications belong to the severe grade that requires reoperation under general anesthesia [24]. Therefore, all of them received a diverting stoma. On the other hand, the complications of the 2 patients who had clinical leakage despite having undergone a concurrent fecal diversion were of mild to moderate grade and required only minor invasive procedures or antibiotic treatment. These results support the suggestion that fecal diversion does not prevent anastomotic leakage but reduces the incidence of severe sequelae [10-12].

Some researchers have reported that a routine WCE is not necessary prior to closure of a diverting stoma [15-17]. One study claimed that a routine WCE was useless, but that it could be used selectively in patients with high-risk clinical indicators, such as postsurgery complications, previous leaks, or abnormal physical features [14]. By contrast, another study suggested that WCE was the best modality for detecting anastomotic leakage, especially from a distal colonic anastomosis [13]. In the present study, 6 of the 126 patients (4.7\%) who had undergone an uLAR with a concurrent fecal diversion suffered a radiologic leakage, which is a nonnegligible proportion. One of these 6 patients did not undergo a stoma restoration. Furthermore, the radiologic leakage rate increased to $35.9 \%$ (14 of 39) in patients who suffered clinical leakage. In 6 of these 14 patients (42.9\%) with a radiologic leakage, the stoma could not be restored. Therefore, a routine WCE appears to be helpful for finding radiologic leakage before stoma restoration, especially in patients who suffer from clinical leakage after an uLAR.

Meanwhile, 118 of the 126 patients (93.7\%) who underwent an ULAR with a concurrent fecal diversion showed no radiologic leakage on the first WCE. There was no rectal anastomotic leakage after stoma restoration. Additionally, 4 of the 20 patients (20\%) who had a radiologic leakage on the first retrograde WCE were shown to have healed spontaneously on serial WCEs. There were no signs or symptoms of anastomosis-leakage-related complications after stoma restoration. Therefore, we suggest that a retrograde WCE is a very effective radiologic procedure before stoma restoration and that normal results on the WCE assure no anastomotic leakage after stoma restoration.

In one study, cavities and strictures at anastomotic sites on the WCE were unfavorable radiologic features associated with nonhealing, but the type of track and its position had no impact on spontaneous healing [12]. That study focused on the disappearance of abnormal features, and if WCE revealed abnormal features, patients did not have the opportunity to undergo stoma restoration. In the present study, however, we focused on abnormal radiologic features favoring stoma restoration and then attempted active restoration of the ileostomy in patients who failed to demonstrate complete healing on the WCE. We categorized four types of abnormal radiologic features on a retrograde WCE: namely, dendritic, horny, saccular, and serpentine. The dendritic and the serpentine types were more frequent in cases with radiologic leakage following clinical leakage than in cases of radiologic leakage only, and none of the dendritic types healed spontaneously. Of the 11 patients who had undergone stoma restoration based on the surgeon's decision as a result of the clinical findings, nine did not complain of any subsequent problems even though persistent leakage was observed on the WCE. Among these patients, two types of leakage-forming cavitary lesions (horny and saccular) had better clinical outcomes after the leakage had been arrested and the stoma restored. The cavity may provide a physical barrier to tissue apposition that slows healing, but may also block the propagation of inflammation. Abdomino-pelvic CT was performed before and after stoma restoration to identify abnor- 
mal fluid, air bubbles, fibrosis, inflammation or a cavity at the anastomotic site. However, the various findings on CT did not influence the clinical course associated with stoma restoration.

This retrospective study had some limitations that were mainly due to the limited number of patients, with only 20 cases of radiologic leakage. Leakage complications due to variations in the technique may have been reduced by studying operations performed by a single surgeon, but some selection bias have existed with regard to the frequency of stoma restoration (11 patients). In addition, some cases of radiologic leakage might have healed before the first WCE imaging, 3 to 4 months after uLAR. This study was based on a single surgeon's experience, so the results may not be generally applicable to other surgeons.

In conclusion, a retrograde WCE study is helpful in detecting radiologic leakage before reversal of a diverting stoma, especially in patients who suffer from clinical leakage after a LAR, and normal results on the WCE may guarantee no anastomotic leakage after a stoma restoration. Identification of radiologic leakage after clinical leakage has a more unfavorable clinical course and rarely heals spontaneously. Otherwise, in cases with specific features on the retrograde WCE, the surgeon needs to deliberately consider the pros and cons of stoma restoration, even though radiologic leakage persists.

\section{CONFLICT OF INTEREST}

No potential conflict of interest relevant to this article was reported.

\section{ACKNOWLEDGMENTS}

This study was supported by grants (to J. C. Kim) from the Asan Institute for Life Sciences (2014-69), the Korea Research Foundation (NRF-2013R1A2A1A03070986), Ministry of Science, ICT, and Future Planning, the Korea Health 21 R\&D Project (HI06C0868 and HI13C1750) and from the Center for Development and Commercialization of Anti-Cancer Therapeutics (A102059), Ministry of Health and Welfare, Republic of Korea.

\section{REFERENCES}

1. Jung SH, Yu CS, Choi PW, Kim DD, Park IJ, Kim HC, et al. Risk factors and oncologic impact of anastomotic leakage after rectal cancer surgery. Dis Colon Rectum 2008;51:902-8.

2. Rullier E, Laurent C, Garrelon JL, Michel P, Saric J, Parneix M. Risk factors for anastomotic leakage after resection of rectal cancer. Br J Surg 1998;85:355-8.

3. Matthiessen P, Hallbook O, Rutegard J, Simert G, Sjodahl R. Defunctioning stoma reduces symptomatic anastomotic leakage after low anterior resection of the rectum for cancer: a randomized multicenter trial. Ann Surg 2007;246:207-14.

4. Enker WE, Merchant N, Cohen AM, Lanouette NM, Swallow C,
Guillem J, et al. Safety and efficacy of low anterior resection for rectal cancer: 681 consecutive cases from a specialty service. Ann Surg 1999;230:544-52.

5. Dehni N, Schlegel RD, Cunningham C, Guiguet M, Tiret E, Parc $R$. Influence of a defunctioning stoma on leakage rates after low colorectal anastomosis and colonic J pouch-anal anastomosis. $\mathrm{Br}$ J Surg 1998;85:1114-7.

6. den Dulk M, Smit M, Peeters KC, Kranenbarg EM, Rutten HJ, Wiggers $\mathrm{T}$, et al. A multivariate analysis of limiting factors for stoma reversal in patients with rectal cancer entered into the total mesorectal excision (TME) trial: a retrospective study. Lancet Oncol 2007;8:297-303.

7. Karanjia ND, Corder AP, Holdsworth PJ, Heald RJ. Risk of peritonitis and fatal septicaemia and the need to defunction the low anastomosis. Br J Surg 1991;78:196-8.

8. Marusch F, Koch A, Schmidt U, Geibetaler S, Dralle H, Saeger $\mathrm{HD}$, et al. Value of a protective stoma in low anterior resections for rectal cancer. Dis Colon Rectum 2002;45:1164-71.

9. Tan WS, Tang CL, Shi L, Eu KW. Meta-analysis of defunctioning stomas in low anterior resection for rectal cancer. Br J Surg 2009; 96:462-72.

10. Wong NY, Eu KW. A defunctioning ileostomy does not prevent clinical anastomotic leak after a low anterior resection: a prospective, comparative study. Dis Colon Rectum 2005;48:2076-9.

11. Bruce J, Krukowski ZH, Al-Khairy G, Russell EM, Park KG. Systematic review of the definition and measurement of anastomotic leak after gastrointestinal surgery. Br J Surg 2001;88:1157-68.

12. Lim M, Akhtar S, Sasapu K, Harris K, Burke D, Sagar P, et al. Clinical and subclinical leaks after low colorectal anastomosis: a clinical and radiologic study. Dis Colon Rectum 2006;49:1611-9.

13. Nicksa GA, Dring RV, Johnson KH, Sardella WV, Vignati PV, Cohen JL. Anastomotic leaks: what is the best diagnostic imaging study? Dis Colon Rectum 2007;50:197-203.

14. Karsten BJ, King JB, Kumar RR. Role of water-soluble enema before takedown of diverting ileostomy for low pelvic anastomosis. Am Surg 2009;75:941-4.

15. Kalady MF, Mantyh CR, Petrofski J, Ludwig KA. Routine contrast imaging of low pelvic anastomosis prior to closure of defunctioning ileostomy: is it necessary? J Gastrointest Surg 2008;12:1227-31.

16. da Silva GM, Wexner SD, Gurland B, Gervaz P, Moon SD, Efron J, et al. Is routine pouchogram prior to ileostomy closure in colonic J-pouch really necessary? Colorectal Dis 2004;6:117-20.

17. Hong SY, Kim do Y, Oh SY, Suh KW. Routine barium enema prior to closure of defunctioning ileostomy is not necessary. J Korean Surg Soc 2012;83:88-91.

18. Law WL, Choi HK, Lee YM, Ho JW, Seto CL. Anastomotic leakage is associated with poor long-term outcome in patients after curative colorectal resection for malignancy. J Gastrointest Surg 2007;11:8-15.

19. McArdle CS, McMillan DC, Hole DJ. Impact of anastomotic leakage on long-term survival of patients undergoing curative resection for colorectal cancer. Br J Surg 2005;92:1150-4. 
20. Mirnezami A, Mirnezami R, Chandrakumaran K, Sasapu K, Sagar P, Finan P. Increased local recurrence and reduced survival from colorectal cancer following anastomotic leak: systematic review and meta-analysis. Ann Surg 2011;253:890-9.

21. Seo SI, Yu CS, Kim GS, Lee JL, Yoon YS, Kim CW, et al. Characteristics and risk factors associated with permanent stomas after sphincter-saving resection for rectal cancer. World J Surg 2013;37: 2490-6.

22. Petersen S, Freitag M, Hellmich G, Ludwig K. Anastomotic leak- age: impact on local recurrence and survival in surgery of colorectal cancer. Int J Colorectal Dis 1998;13:160-3.

23. Karanjia ND, Corder AP, Bearn P, Heald RJ. Leakage from stapled low anastomosis after total mesorectal excision for carcinoma of the rectum. Br J Surg 1994;81:1224-6.

24. Strasberg SM, Linehan DC, Hawkins WG. The accordion severity grading system of surgical complications. Ann Surg 2009;250: 177-86. 